Akinori Nakamura • Narihiro Minami • Toshiaki Kamitani

Keiko Kamakura $\cdot$ Kiichi Arahata $\cdot$ Shin-ichi Takeda

\title{
A novel Sac I RFLP in the 3' untranslated region of the myotonin protein kinase gene
}

Received: 15 October, 1998 / Accepted: 31 October, 1998

\begin{abstract}
We found a novel Sac I polymorphism downstream of CTG repeats in the $3^{\prime}$ untranslated region of the myotonin protein kinase (MT-PK) gene. A C to G transition at nucleotide 13,590 in the gene was revealed by Southern blotting and confirmed by sequencing analyses. The allelic frequency of the $\mathrm{C}: \mathrm{G}$ polymorphism in 63 unrelated Japanese individuals was estimated to be 0.98: 0.02. When Southern blotting is employed in the analysis of the CTG repeat length in the $M T-P K$ gene, this $S a c$ I polymorphism should be taken into consideration.
\end{abstract}

Key words Myotonic dystrophy $\cdot$ Myotonin protein kinase gene · Polymorphism · Sac I digestion · 3'-untranslated region

\section{Introduction}

Myotonic dystrophy (DM) is an autosomal dominant multisystem disorder associated with the CTG repeat expansion within the $3^{\prime}$ non-coding region of the myotonin protein kinase $(M T-P K)$ gene. The $M T-P K$ gene has been localized

S. Takeda $(\square)$

Department of Molecular Genetics, National Institute of

Neuroscience, National Center of Neurology and Psychiatry

(NCNP), 4-1-1 Ogawa-higashi cho, Kodaira, Tokyo 187-8502, Japan

Tel. and Fax +81-42-346-3864

e-mail: takeda@ncnaxp.ncnp.go.jp

A. Nakamura

Department of Medicine (Neurology), Shinshu University School of Medicine, Matsumoto, Japan

N. Minami

Department of Laboratory Medicine, Musashi Hospital, National

Center of Neurology and Psychiatry, Tokyo, Japan

T. Kamitani · K. Kamakura

Third Department of Internal Medicine, National Defense Medical

College, Saitama, Japan

\section{K. Arahata}

Department of Neuromuscular Research, National Institute of Neuroscience, National Center of Neurology and Psychiatry, Tokyo, Japan at 19q 13.3 (Tsilfidis et al. 1991). Analysis of the CTG repeat length is diagnostically important for this disorder and is usually examined by Southern blotting.

To detect the expansion of the CTG repeat, a 1.4-kb Bam H I genomic fragment containing the $3^{\prime}$ end of the $M T$ $P K$ gene, designated pM10M-6 (Brook et al. 1992) has been used as a probe for Southern blotting (Fig. 1). We have used a $0.66-\mathrm{kb}$ Pst I/Hinc II subfragment (pM10M-6N) of the original $B a m \mathrm{H}$ I fragment to reduce non-specific background signals in the Southern blotting (Nakamura et al. 1996). This new probe recognized the fragment containing the unstable trinucleotide CTG repeat after digestion of genomic DNA with various restriction enzymes, such as $B a m \mathrm{H}$ I, $B g l$ I, Eco R I, Hind III, Pst I, and Sac I.

\section{Source and description}

We encountered a 63-year-old man showing neurogenic muscular atrophy and cerebellar hypoplasia but not having myotonia. Since this patient had a "hatchet face", one of the characteristic symptoms of DM, we examined the CTG repeat length of the $M T-P K$ gene. Southern blot analysis with the pM10M-6N probe revealed no expansion of the CTG repeat when the genome was digested by $B a m \mathrm{H} \mathrm{I}, B g l$ I, EcoR I, Hind III, or Pst I. However, when the genome was digested by $S a c$ I, alleles of two different sizes were detected (3.5 kb [A1] and 2.0kb [A2]) (Fig. 2A). These results showed that the polymorphic Sac I site was located downstream of the CTG repeat within exon 15 which contained the $3^{\prime}$ untranslated region. Sequence analysis revealed that the polymorphic site was a $\mathrm{C}$ to $\mathrm{G}$ transition at nucleotide position 13,590 (Mahadevan et al. 1993) of the $M T-P K$ gene.

The genomic DNA fragment containing this polymorphic site was also amplified by the polymerase chain reaction (PCR) method with sense (base pairs 13,386 to 13,405: DM15-F: 5'-TATCGTTGGTTCGCAAAGTG-3') and antisense (base pairs 13,660 to 13,679: DM15-R: 5'CTCAGTGCATCCAAAACGTG-3') primers. PCR reac- 
Fig. 1 Scheme showing the $3^{\prime}$ untranslated region of the mytonin protein kinase gene. Sequence analysis of proband revealed that the polymorphic site was a $C$ to $G$ transition at nucleotide position 13,590 of the gene and resulted in a new Sac I site. Restriction sites used for the Southern blotting, and the location of the original probe (pM10M-6) and newly generated probe (pM10M-6N) are also shown

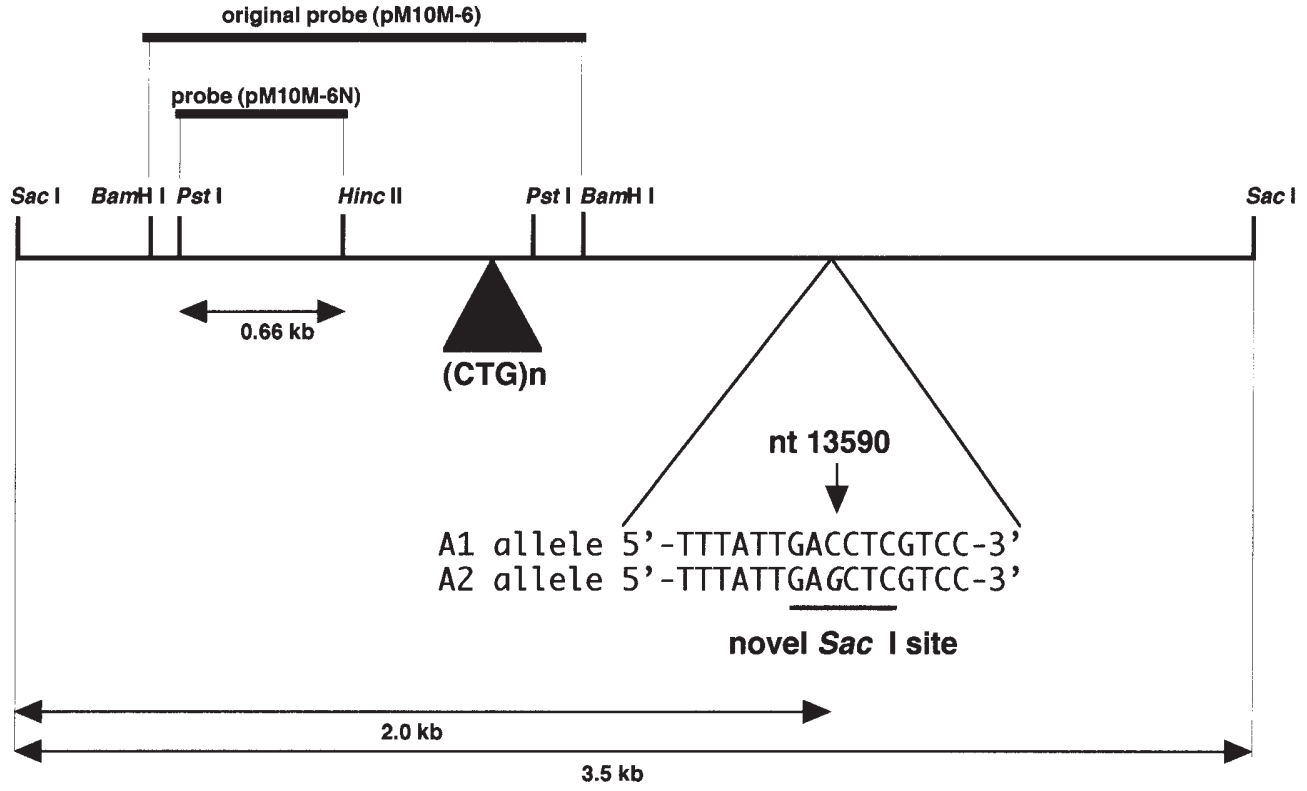

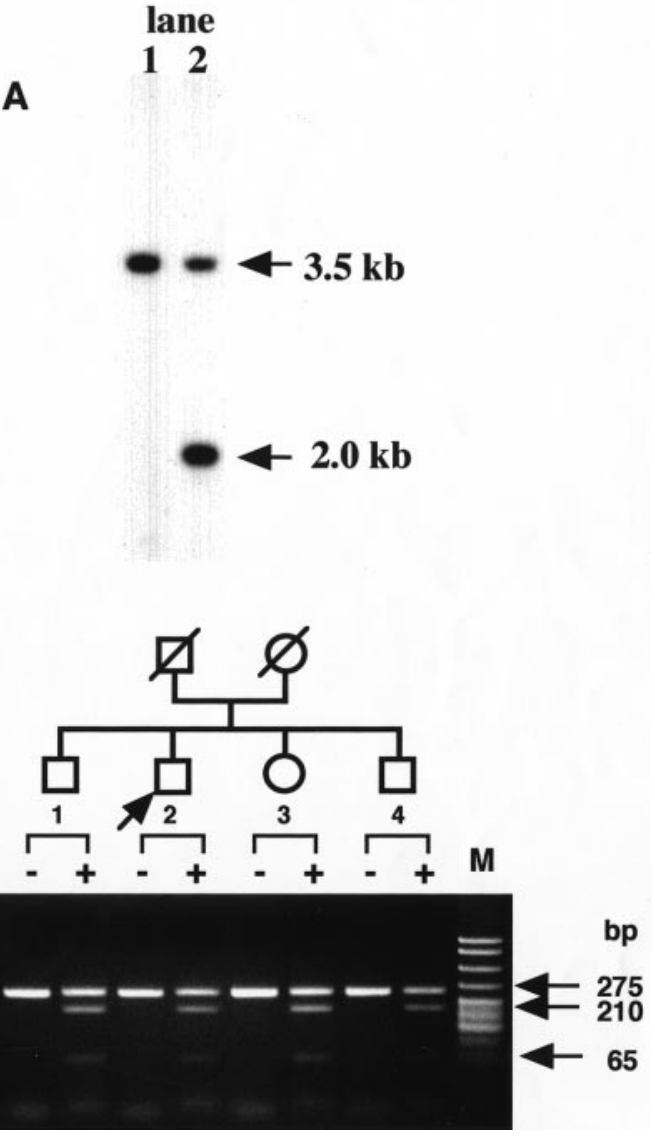

Fig. 2 A Southern blotting analysis of the genomic DNA digested by Sac I. The pM10M-6N probe detected a $3.5-\mathrm{kb}$ band in the normal control (lane 1$)$, and two bands $(3.5 \mathrm{~kb}$ and $2.0 \mathrm{~kb})$ in the proband (lane 2). B Analysis of Sac I-digested polymerase chain reaction (PCR) products in a $4.0 \%$ NuSieve (FMC Corp., Chicago, IL) agarose gel stained with ethidium bromide. A Sac I site was found in one of the alleles from the proband (arrow), and produced fragments of $210 \mathrm{bp}$ and $65 \mathrm{bp}$, together with a 275-bp undigested band from another allele (lane 1). Note that three siblings in the family were also heterozygous for this Sac I polymorphism (lanes 2-4). Lane M, DNA molecular weight markers tions were performed in a total volume of $50 \mu$ l containing $100 \mathrm{ng}$ genomic DNA, $100 \mathrm{ng}$ of each primer, and $0.5 \mathrm{mM}$ each of dNTPs. Initial denaturation at $94^{\circ} \mathrm{C}$ for $5 \mathrm{~min}$ was followed by 30 cycles with denaturation at $94^{\circ} \mathrm{C}$ for $1 \mathrm{~min}$, annealing at $62^{\circ} \mathrm{C}$ for $1 \mathrm{~min}$, and extension at $72^{\circ} \mathrm{C}$ for $1 \mathrm{~min}$. Finally, a 10 -min extension step at $72^{\circ} \mathrm{C}$ was added. Sac I digestion of the amplified fragment from the patient (proband) resulted in two alleles. The allele A1 did not contain the Sac I site and produced an undigested fragment of $275 \mathrm{bp}$, while the allele A2 having the Sac I site produced two fragments, of $210 \mathrm{bp}$ and $65 \mathrm{bp}$. Three siblings in the family were found to be heterozygous for the Sac I polymorphism and none of them had any symptoms of DM (Fig. 2B).

\section{Polymorphism and allele frequency}

We estimated the allele frequency by analysis of 126 chromosomes of 63 unrelated Japanese individuals. The allele frequency was: A1, 0.98 and A2, 0.02 and the combined observed heterozygosity in the 63 individuals with $S a c$ I digestion was 0.04 . Thus, when Southern blotting is employed in the analysis of the MT-PK gene, this Sac I polymorphism should be taken into consideration.

Acknowledgments We thank Drs. D.J. Shaw and P.S. Harper for providing the pM10M-6 probe. This work was supported by a Research Grant (4A-1) for Nervous and Mental Disorders from the Ministry of Health and Welfare of Japan, and by the Fugaku Trust for Medical Research.

\section{References}

Brook JD, McCurrach ME, Harley HG, Buckler AJ, Church D, Aburatani H, Hunter K, Stanton VP, Thirion JP, Hudson T, Sohn R, Zemelman B, Dnell RG, Rundle SA, Crow S, Davies J, Juvonen V, 
Buxton J, Jones C, Juvonen V, Johnson K, Harper PS, Shaw DJ, Housman DE (1992) Molecular basis of myotonic dystrophy: Expansion of a trinucleotide (CTG) repeat at the $3^{\prime}$ end of a transcript encoding a protein kinase family member. Cell 68: 799-808

Mahadevan MS, Amemiya C, Jansen G, Sabourin L, Baird S, Neville CE, Wormskamp N, Segers B, Batzer M, Lamerdin J, de Jong P, Wieringa B, Korneluk RG (1993) Structure and genomic sequence of the myotonic dystrophy (DM kinase) gene. Hum Mol Genet 2: 299-403
Nakamura A, Kojo T, Arahata K, Takeda S (1996) Reductions of serum IgG level and peripheral T-cell counts are correlated with CTG repeat lengths in myotonic dystrophy patients. Neuromuscril Disord 6: 203-210

Tsilfidis C, MacKenzie AE, Shutler G, Leblond S, Bailly J, Johnson K, Williamson R, Siegel-Bartelt J, Korneluk RG, Shelbourne P (1991) D19S51 is closely linked with and maps distal to the myotonic dystrophy locus on 19q. Am J Hum Genet 49: 961-965 